\title{
Color stability of provisional restorative materials with different fabrication methods
}

\author{
So-Yeon Song ${ }^{1,2+}$, Yo-Han Shin ${ }^{3+}$, Jeong-Yol Lee ${ }^{4 *}$, Sang-Wan Shin ${ }^{5}$ \\ ${ }^{1}$ Department of Biomedical Science, Graduate School of Korea University, Seoul, Republic of Korea \\ ${ }^{2}$ Institute for Clinical Dental Research, Korea University Medical Center, Republic of Korea \\ ${ }^{3}$ Department of Medicine, Graduate School of Korea University, Seoul, Republic of Korea \\ ${ }^{4}$ Department of Advanced Prosthodontics, Korea University Guro Hospital, Seoul, Republic of Korea \\ ${ }^{5}$ Institute for Clinical Dental Research, Korea University Medical Center, Seoul, Republic of Korea
}

\begin{abstract}
PURPOSE. The aim of this study was to investigate and compare the color stability of provisional restorative materials fabricated by 3D printing, dental milling, and conventional materials. MATERIALS AND METHODS. For the experimental groups, two commercially available 3D-printing provisional resins (E-Dent 100; EnvisionTEC $\mathrm{GmbH}$, Germany \& VeroGlaze ${ }^{\mathrm{TM}}$; Stratasys ${ }^{\circledR}$, USA), two dental milling blocks (PMMA Disk; Yamahachi Dental Co., Japan \& Telio ${ }^{\circledR}$ CAD; Ivoclar Vivadent AG, Liechtenstein), and two conventional materials (Alike ${ }^{\mathrm{TM}}$; GC Co., Japan \& Luxatemp automix plus; DMG, Germany) were used. The water sorption and solubility test were $(n=10$, respectively) carried out according to ISO4049:2000 (International Standards Organization, Geneva, Switzerland). For the color stability test $(n=10)$, coffee and black tea were used as staining solutions, and the specimens were stored for 12 weeks. Data were analyzed by one-way ANOVA and Tukey's HSD using SPSS version 22.0 (SPSS Inc. Chicago, IL, USA) $(P<.05)$. RESULTS. Alike and Veroglaze showed the highest values and Luxatemp showed the lowest water sorption. In the color stability test, the $\Delta \mathrm{E}$ of conventional materials varied depending on the staining solution. PMMA milling blocks showed a relatively low $\Delta \mathrm{E}$ up to 4 weeks, and then significantly increased after 8 weeks $(P<.05)$. 3D-printed materials exhibited a high $\Delta \mathrm{E}$ or a significant increase over time $(P<.05)$. CONCLUSION. The degree of discoloration increased with time, and a visually perceptible color difference value $(\Delta \mathrm{E})$ was shown regardless of the materials and solutions. PMMA milled and 3D-printed materials showed more rapid change in discoloration after 8 weeks. [J Adv Prosthodont 2020;12:259-64]
\end{abstract}

KEYWORDS: Provisional restorative materials; 3D printing dental materials; Dental PMMA milling materials; Color stability; Water sorption; Solubility; Spectrophotometer; CIELAB color space

\section{INTRODUCTION}

Provisional restorations such as crowns and bridges are widely used in fixed partial denture (FPD) treatment. They

Corresponding author:

Jeong-Yol Lee

Department of Advanced Prosthodontics, Korea University Guro Hospital, Institute for Clinical Dental Research, Guro Hospital, Korea University,

148 Gurodong-gil, Guro-gu, Seoul 08305, Republic of Korea

Tel. +82226261922: e-mail,wddc@korea.ac.kr

Received September 5, 2019 / Last Revision June 23, 2020 / Accepted

August 21, 2020

(C) 2020 The Korean Academy of Prosthodontics

This is an Open Access article distributed under the terms of the Creative Commons Attribution Non-Commercial License (http://creativecommons. org/licenses/by-nc/4.0) which permits unrestricted non-commercial use, distribution, and reproduction in any medium, provided the original work is properly cited.

+ These authors contributed equally to this work. act as a thermal insulator that protects the prepared tooth structure, stabilizes occlusal relationships, and determines the aesthetic, functional, and therapeutic effectiveness of the treatment before placement of definitive dental prosthesis. Materials used for provisional restoration should provide sufficient mechanical strength, wear resistance, and color stability to satisfy biological and aesthetic requirements. ${ }^{1,2}$

Discoloration of provisional crowns and bridges during long-term treatment may lead to patient dissatisfaction and additional cost for replacement. ${ }^{3}$ Therefore, color stability is an important factor in the selection of provisional materials, especially in aesthetic areas. There are several factors that may affect the amount of discoloration including incomplete polymerization, water sorption, chemical reactivity, surface roughness of the restoration, diet, and oral hygiene. ${ }^{3,4}$ Various studies have reported on the influence of staining materials such as tea, coffee, and red wine on provisional 
materials. ${ }^{4,5}$ According to a previous study, conventional temporary material bis-acryl-methacrylate-based resins were more color-stable compared to the methyl/ethyl methacrylate-based resins. ${ }^{4}$ In contrast, a different study reported that methacrylate-based resins exhibited the highest color stability regardless of polishing technique and staining agent used. $^{3}$

Recently, the advent of computer-aided design and computer-aided manufacturing (CAD/CAM) technology has contributed to the development of different milling systems. Several studies ${ }^{6,7}$ have suggested the use of PMMA block for milling due to its superior physical and mechanical properties. This pre-polymerized material promotes good homogeneity without polymerization shrinkage. Based on a previous study, CAD/CAM PMMA material showed the best color stability among other provisional materials. ${ }^{8} 3 \mathrm{D}$ printing is now further advancing digital dentistry and can be used in the production of drill guides for dental implants; physical models for prosthodontics, orthodontics, and surgery; manufacture of dental, craniomaxillofacial, and orthopedic implants; and fabrication of copings and frameworks for implant and dental restorations. ' In addition, it allows accurate and repeatable fabrication of provisional restoration in a short time period. ${ }^{10}$ Although there are several review papers discussing the use and benefits of $3 \mathrm{D}$ printing in dentistry, studies on its physical and mechanical properties are lacking, especially regarding color stability.

Therefore, this study aimed to compare the color stability of different commercially available provisional restorative materials after immersion in commonly consumed beverages for varying time intervals. The null hypothesis of this study was there is no difference in color stability of provisional restorative materials during the long-term discoloration.

\section{MATERIALS AND METHODS}

Six provisional materials with different chemical compositions and fabrication methods were evaluated, as shown in Table 1 . Two commercially available 3D-printing provisional resins (E-Dent 100, VeroGlaze), two dental milling blocks (PMMA Disk, Telio ${ }^{\circledR}$ CAD), and two conventional materials
(Alike $^{\text {TM }} \&$ Luxatemp automix plus) were used.

Water sorption and solubility tests were based on the content of ISO 4049: 2009, Dentistry-Polymer-based restorative materials. ${ }^{11}$ A total of 60 specimens, 10 specimens per group, were fabricated with $15 \mathrm{~mm}$ (diameter) $\times 1$ $\mathrm{mm}$ (thickness) disk shape using a stainless steel mold. Experimental values were measured with the following variables: $\mathrm{m} 1, \mathrm{~m} 2, \mathrm{~m} 3, \mathrm{~V}$.

For the measurement of $\mathrm{m} 1$, the specimens were stored in a dry oven (Forced Convection Dry Oven, Daihan Scientific, Daihan Scientific, Daegu, Korea) at $37^{\circ} \mathrm{C}$ for 24 hours and then weighed ( $\mathrm{m} 1$ ) with analytical balances (AR2140, Ohaus, Parsippany, NJ, USA). The measurement was repeated at intervals of 24 hours, and this value was repeatedly recorded as $\mathrm{m} 1$ until the error of the weight was stabilized at $0.001 \mathrm{~g}$ or less. The volume (V) of the specimen was measured using digital calipers (500-181, Mitutoyo, Mitutoyo, Kawasaki, Japan) with a resolution of $0.01 \mathrm{~mm}$. The diameter was measured twice and the thickness was measured 5 times per specimen before the determination of the average value after $\mathrm{m} 1$.

For the measurement of $\mathrm{m} 2$, pre-treated specimens were immersed vertically in $37^{\circ} \mathrm{C}$ distilled water for 7 days. During immersion, the distance between the specimens was kept at $3 \mathrm{~mm}$ to avoid contact. After 7 days, the immersed specimens were removed from the water. For accurate measurements, the specimens were wiped with a dry towel until moisture was removed, dried in the air for 15 seconds, and weighed (m2) after 60 seconds.

For the measurement of $\mathrm{m} 3$, the weighed specimens were measured in the same manner as the pretreated (m1) specimens and were repeated every 24 hours until the values stabilized.

Calculation of the value for water sorption ( $\left.\mathrm{W}_{\mathrm{sp}}\right)$ and solubility $\left(W_{s l}\right)$ for each specimen is expressed in $\mu \mathrm{g} / \mathrm{mm}^{3}$ from the following equation:

$$
W_{s p}=\frac{m^{2}-m_{3}}{V}
$$

$: \mathrm{m} 2$ is the mass of the specimen, in micrograms $(\mu \mathrm{g})$, after immersion in water

Table 1. Provisional prosthetic materials used in this study

\begin{tabular}{|c|c|c|c|c|c|}
\hline Product & Resin type & Fabrication method & Manufacturer & Lot no. & $\begin{array}{c}\text { No. of } \\
\text { specimens }\end{array}$ \\
\hline Alike & Polymethyl methacrylate & Powder/Paste & GC Co., Tokyo, Japan & 1405122 & 10 \\
\hline $\begin{array}{l}\text { Luxatemp } \\
\text { Automix plus }\end{array}$ & Bis-acryl methacrylate & $\begin{array}{l}2 \text { pastes } \\
\text { Auto-mix syringe }\end{array}$ & DMG, Hamburg, Germany & 750120 & 10 \\
\hline VeroGlaze & Bio-compatible photopolymer & 3D-printing & Stratasys, Edina, MN, USA & MED620 & 10 \\
\hline E-dent 100 & Acrylic resins & Materials & EnvisionTEC GmbH, Gladbeck, Germany & & 10 \\
\hline PMMA Disk & Polymethyl methacrylate & Milling disk & Yamahachi Dental Co., Gamagori, Japan & L104 & 10 \\
\hline Telio CAD & Polymethyl methacrylate & Milling block & Ivoclar Vivadent AG, Schaan, Liechtenstein & U41045 & 10 \\
\hline
\end{tabular}


$: \mathrm{m} 3$ is the reconditioned mass of the specimen, in micrograms $(\mu \mathrm{g})$

$: \mathrm{V}$ is the volume of the specimen, in cubic millimetres $\left(\mathrm{mm}^{3}\right)$

$$
W_{s l}=\frac{m_{1}-m_{3}}{V}
$$

: $\mathrm{m} 1$ is the "conditioned" mass of the specimen, in micrograms $(\mu \mathrm{g})$

: $\mathrm{m} 3$ and $\mathrm{V}$ are as given in water sorption formula

For the color stability test, a total of 120 provisional discs with similar shade (A2) were fabricated according to the manufacturer's instructions; 10 specimens for each group were prepared. Each had a measurement of $10 \mathrm{~mm}$ (diameter) $\times 2 \mathrm{~mm}$ (thickness) and the dimension of the specimen was referred to ADA No.12. ${ }^{12}$ All specimens were polished using 600-grit silicon carbide abrasive paper under water cooling for initial roughness standardization. Each group was further subdivided into two different staining solutions; coffee and black tea were used for this study.

Coffee was prepared by mixing $8 \mathrm{~g}$ of coffee powder (Iguaçu Company Instant Coffee, Cornélio Procópio, Brazil) with $300 \mathrm{cc}$ of boiling water for 10 minutes and then filtered using filter paper. Black tea was prepared by placing one tea bag (Lipton, Unilever Korea Co., Ltd., Seoul, Korea) in $500 \mathrm{cc}$ of boiling water for 15 minutes. All specimens were stored in distilled water for 24 hours before immersion. Each sample was stored in solution in a $37^{\circ} \mathrm{C}$ Dry Oven (Daihan Scientific, Daegu, Korea) in a light-shielded container. The staining solution was refreshed daily, and the experiment was carried out for 3 months.

The $L^{*}, a^{*}$, and $b^{*}$ values of each specimen were recorded under exposure of sunlight D65 light source containing ultraviolet rays through a spectrocolorimeter (Xrite Benchtop Spectrophotometer Color i5, X-Rite, Inc., Grand Rapids, MI, USA) using the CIELAB color space (Fig. 1). The $\mathrm{L}, \mathrm{a}$, and $\mathrm{b}$ values of the specimen before and after precipitation of the staining solution stored in the distilled water for 1 day were used as the control, and values were measured on $1,2,4,8$, and 12 weeks. The $L^{*}$ value indicates the brightness of an object, $a^{*}$ describes the color levels between red and green, while $b^{*}$ describes color levels between yellow and blue. The results were recorded as $\Delta \mathrm{L}$, $\Delta \mathrm{a}$, and $\Delta \mathrm{b}$ values through the following respective calculations and the total color difference value $\Delta \mathrm{E}$ was calculated using the formula.

$$
\begin{aligned}
& \Delta \mathrm{L}= \mathrm{L} \text { value of each experimental group } \\
&-\mathrm{L} \text { value of control group } \\
& \Delta \mathrm{a}= \text { a value of each experimental group } \\
&- \text { a value of control group } \\
& \Delta \mathrm{b}= \mathrm{b} \text { value of each experimental group } \\
&-\mathrm{b} \text { value of control group } \\
& \Delta \mathrm{E}\left(\mathrm{L}^{*} \mathrm{a}^{*} \mathrm{~b}^{*}\right)=\left[\left(\Delta \mathrm{L}^{*}\right)^{2}+\left(\Delta \mathrm{a}^{*}\right)^{2}+\left(\Delta \mathrm{b}^{*}\right)^{2}\right]^{1 / 2}
\end{aligned}
$$

All statistical tests were analyzed using SPSS version 22.0 (IBM, Armonk, NY, USA) ( $P=.05$ ). The normality of data distribution was verified using Kolmologov-Smirnov test. The data of water sorption and solubility test were content with both the normality and homogeneity of variance. One-way ANOVA was used to analyze the data, Tukey's HSD was used for post-analysis $(P=.05)$. The data of color stability test were conducted with nonparametric analysis using Kruskal-Wallis test and Mann-Whitney U-test because these data were partially content with the normality.
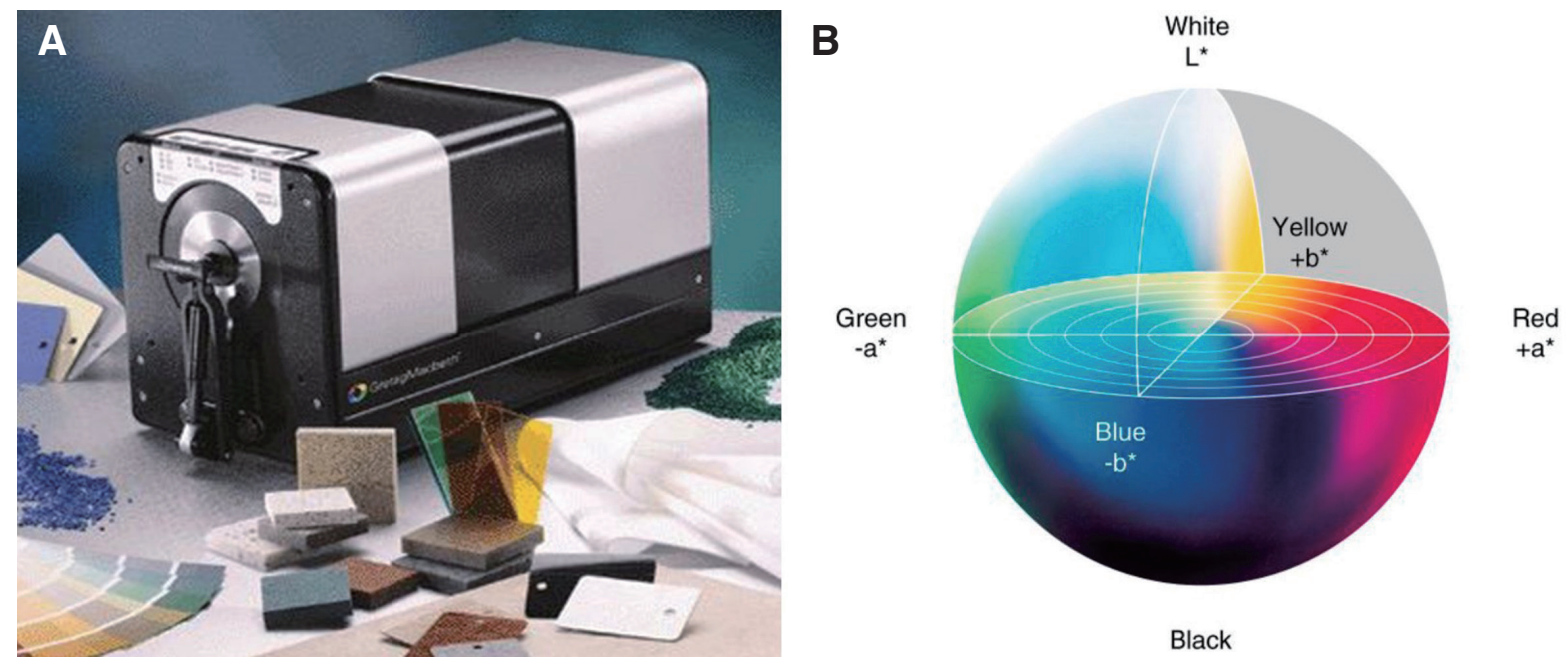

Fig. 1. (A) A spectrocolorimeter (Xrite Benchtop Spectrophotometer Color i5, Xrite, USA), (B) The CIELAB color space (CIE L*a*b*; or abbreviated as Lab color space). 


\section{RESULTS}

The mean values $( \pm$ SD) of water sorption and solubility of thermoplastic denture base resins for each group are presented in Table 2. Alike and VeroGlaze showed the highest water absorption with significant difference from other groups $(P<.05)$. Luxatemp showed the lowest water absorption $(P<.05)$. For water solubility, Alike and E-dent 100 had significantly high values $(P<.05)$, while the four other groups had values lower than $1 \mu \mathrm{g} / \mathrm{mm}^{3}$.

The $\Delta \mathrm{E}$ values or degree of discoloration after 1, 2, 4, 8, and 12 weeks of storage in coffee solution are presented in Table 3. The color differences $(\Delta \mathrm{E})$ of Alike, PMMA disk, and E-dent 100 showed no significant difference after staining with coffee solution for 12 weeks, $(P>.05)$, while that of Luxatemp significantly decreased $(P<.05)$. The CAD/ CAM milling block, Telio CAD, was stable with relatively small color difference $(\Delta \mathrm{E})$ until 4 weeks, but sharply increased at 8 and 12 weeks $(P<.05)$. VeroGlaze showed similar color difference $(P>.05)$ except for the result after 2 weeks of staining $(P<.05)$.

The $\Delta \mathrm{E}$ values or degree of discoloration after 1, 2, 4, 8, and 12 weeks of storage in black tea solution are presented in Table 4. In the black tea color stability test, Alike significantly increased in $\Delta \mathrm{E}$ with time $(P<.05)$, while Luxatemp showed no change in $\Delta \mathrm{E}$ over time $(P>.05)$. Similar to the experimental results of coffee, the results for the first 4 weeks tended to be higher than those after 8 weeks. The two 3D-printing provisional resins (E-Dent 100 \& VeroGlaze) and two dental milling blocks (PMMA Disk \& Telio ${ }^{\circledR} \mathrm{CAD}$ ) showed significantly higher color difference on 12 weeks results than at $1-4$ weeks $(P<.05)$.

\section{DISCUSSION}

Although provisional restorations are intended for a limited period of use, color stability in these materials is a concern especially in the aesthetic zone. Therefore, in this study, samples were immersed in staining solution for 12 weeks to analyze long-term color stability. Visual assessment of color perception is a subjective, physiological, and psychological process that varies among examiners. ${ }^{8}$ On the other hand, spectrophotometry provides measurements in CIELAB units ${ }^{13}$ that can be analyzed mathematically to compare the color

Table 2. Mean and standard deviation of water absorption and solubility test $\left(\mu \mathrm{g} / \mathrm{mm}^{3}\right)$

\begin{tabular}{|c|c|c|c|c|c|c|}
\hline & Alike & Luxatemp & VeroGlaze & E-dent M & PMMA Disk & Telio CAD \\
\hline Water sorption (Mean \pm SD) & $32.23 \pm 5.93^{\mathrm{a}}$ & $14.15 \pm 1.30$ & $35.02 \pm 1.43^{a}$ & $20.08 \pm 2.27^{b}$ & $23.16 \pm 1.25^{\mathrm{b}, \mathrm{c}}$ & $19.13 \pm 1.41^{\circ}$ \\
\hline Kolmogorov-smirnov (p) & 0.200 & 0.144 & 0.200 & 0.200 & 0.200 & 0.200 \\
\hline Water solubility (Mean \pm SD) & $3.54 \pm 1.81^{\star}$ & $0.38 \pm 0.56^{\star *}$ & $0.52 \pm 0.80^{\star \star}$ & $2.78 \pm 1.49^{\star}$ & $0.84 \pm 0.61^{\star \star}$ & $0.97 \pm 0.47^{\text {*ᄎ* }}$ \\
\hline Kolmogorov-smirnov (p) & 0.200 & 0.200 & 0.200 & 0.200 & 0.200 & 0.190 \\
\hline
\end{tabular}

* In the water sorption test, values denoted by same letters have no significant differences $(P>.05)$. In the results of water solubility test, values with the same number of asterisk $\left({ }^{*},{ }^{* \star},{ }^{\star \star *}\right)$ have no significant differences $(P>.05)$. In the Kolmogorov-smirnov test, all groups were contented with the normality $(P>.05)$. For the Levene test, the $P=.001, P=.010$ respectively for water sorption, solubility.

Table 3. The mean, standard deviation and the percentile $(25,50,75)$ of $\Delta \mathrm{E}$ after $1,2,4,8$, and 12 weeks of staining with coffee $(25=1$ st quartile, $50=$ median, $75=3$ rd quartile $)$

\begin{tabular}{|c|c|c|c|c|c|c|}
\hline $\begin{array}{c}\text { Coffee } \\
(\text { Mean } \pm \text { SD) } \\
P(25,50,75)\end{array}$ & Alike & Luxatemp & VeroGlaze & E-dent M & PMMA Disk & Telio CAD \\
\hline$\Delta E_{-} 1 \mathrm{~W}$ & $\begin{array}{c}6.69 \pm 2.39 \\
(4.77,6.47,8.44)\end{array}$ & $\begin{array}{c}14.70 \pm 2.38 \\
(12.93,13.97,16.65)\end{array}$ & $\begin{array}{c}14.96 \pm 4.92 \\
(11.92,14.52,18.38)\end{array}$ & $\begin{array}{c}20.70 \pm 3.28 \\
(17.29,20.39,23.70)\end{array}$ & $\begin{array}{c}5.29 \pm 2.78 \\
(3.30,4.30,6.96)\end{array}$ & $\begin{array}{c}4.44 \pm 2.23 \\
(2.66,4.02,5.66)\end{array}$ \\
\hline$\Delta \mathrm{E} \_2 \mathrm{~W}$ & $\begin{array}{c}7.15 \pm 3.08 \\
(4.43,7.56,9.09)\end{array}$ & $\begin{array}{c}14.08 \pm 3.79 \\
(11.62,14.68,16.39)\end{array}$ & $\begin{array}{c}5.05 \pm 3.07 \\
(3.19,3.74,6.85)\end{array}$ & $\begin{array}{c}20.38 \pm 4.77 \\
(16.82,21.16,24.13)\end{array}$ & $\begin{array}{c}8.76 \pm 3.47 \\
(7.07,8.19,9.52)\end{array}$ & $\begin{array}{c}6.54 \pm 4.12 \\
(3.83,4.87,8.85)\end{array}$ \\
\hline$\Delta \mathrm{E}_{-} 4 \mathrm{~W}$ & $\begin{array}{c}7.70 \pm 2.70 \\
(5.13,7.67,9.67)\end{array}$ & $\begin{array}{c}17.35 \pm 4.64 \\
(13.38,16.65,19.96)\end{array}$ & $\begin{array}{c}14.97 \pm 1.51 \\
(13.52,14.67,16.52)\end{array}$ & $\begin{array}{c}14.80 \pm 3.37 \\
(12.28,12.90,18.02)\end{array}$ & $\begin{array}{c}5.53 \pm 1.22 \\
(4.53,5.05,6.48)\end{array}$ & $\begin{array}{c}4.06 \pm 0.77 \\
(3.45,4.09,4.54)\end{array}$ \\
\hline$\Delta \mathrm{E} \_8 \mathrm{~W}$ & $\begin{array}{c}10.39 \pm 1.17 \\
(9.26,10.43,11.47)\end{array}$ & $\begin{array}{c}4.42 \pm 0.61 \\
(3.98,4.47,4.79)\end{array}$ & $\begin{array}{c}17.35 \pm 3.69 \\
(15.11,15.61,19.92)\end{array}$ & $\begin{array}{c}19.57 \pm 3.50 \\
(16.12,19.35,22.69)\end{array}$ & $\begin{array}{c}10.27 \pm 1.04 \\
(9.39,10.22,11.33)\end{array}$ & $\begin{array}{c}22.60 \pm 3.71 \\
(20.03,21.36,25.02)\end{array}$ \\
\hline$\Delta \mathrm{E}_{-} 12 \mathrm{~W}$ & $\begin{array}{c}9.89 \pm 1.95 \\
(7.98,9.96,11.40)\end{array}$ & $\begin{array}{c}4.20 \pm 1.57 \\
(3.44,3.85,4.50)\end{array}$ & $\begin{array}{c}19.80 \pm 2.85 \\
(17.69,18.79,21.47)\end{array}$ & $\begin{array}{c}20.01 \pm 3.00 \\
(18.47,20.11,21.63)\end{array}$ & $\begin{array}{c}10.35 \pm 1.14 \\
(9.42,10.28,11.27)\end{array}$ & $\begin{array}{c}21.07 \pm 2.86 \\
(18.54,21.11,23.62)\end{array}$ \\
\hline
\end{tabular}

${ }^{*}$ The darker grey cell represent significantly greater color difference $(\Delta \mathrm{E})$ than that of light grey cell within each experimental group $(P<.05)$. It have shown the difference of $\Delta \mathrm{E}$ over time staining with coffee and does not represent the difference among materials (Only longitudinally). 
Table 4. The mean, standard deviation (SD) and the percentile (P; 25, 50, 75) of $\Delta \mathrm{E}$ after $1,2,4,8$, and 12 weeks of staining with black tea $(25=1$ st quartile, $50=$ median, $75=3$ rd quartile)

\begin{tabular}{|c|c|c|c|c|c|c|}
\hline $\begin{array}{c}\text { Black Tea } \\
(\text { Mean } \pm \text { SD) } \\
P(25,50,75)\end{array}$ & Alike & Luxatemp & VeroGlaze & E-dent 100 & PMMA Disk & Telio CAD \\
\hline$\Delta \mathrm{E}_{-} 1 \mathrm{~W}$ & $\begin{array}{c}4.26 \pm 1.08 \\
(3.75,4.63,4.94)\end{array}$ & $\begin{array}{c}7.62 \pm 3.07 \\
(5.91,6.77,8.61)\end{array}$ & $\begin{array}{c}2.06 \pm 1.13 \\
(1.07,2.37,2.74)\end{array}$ & $\begin{array}{c}12.48 \pm 1.87 \\
(11.42,12.27,13.31)\end{array}$ & $\begin{array}{c}3.30 \pm 0.80 \\
(2.71,3.29,3.90)\end{array}$ & $\begin{array}{c}2.84 \pm 0.97 \\
(1.91,3.05,3.58)\end{array}$ \\
\hline$\Delta \mathrm{E} \_2 \mathrm{~W}$ & $\begin{array}{c}5.93 \pm 1.56 \\
(4.38,5.93,6.99)\end{array}$ & $\begin{array}{c}7.90 \pm 3.58 \\
(5.84,7.71,9.17)\end{array}$ & $\begin{array}{c}4.87 \pm 2.56 \\
(3.67,4.04,5.78)\end{array}$ & $\begin{array}{c}13.06 \pm 1.86 \\
(12.03,12.79,14.00)\end{array}$ & $\begin{array}{c}5.05 \pm 0.88 \\
(4.56,5.05,5.65)\end{array}$ & $\begin{array}{c}4.93 \pm 1.03 \\
(4.22,4.64,6.23)\end{array}$ \\
\hline$\Delta \mathrm{E} \_4 \mathrm{~W}$ & $\begin{array}{c}7.90 \pm 1.46 \\
(7.12,8.07,8.79)\end{array}$ & $\begin{array}{c}11.37 \pm 3.51 \\
(8.93,11.49,12.78)\end{array}$ & $\begin{array}{c}6.93 \pm 0.88 \\
(6.08,7.11,7.59)\end{array}$ & $\begin{array}{c}12.51 \pm 2.41 \\
(11.01,11.60,13.66)\end{array}$ & $\begin{array}{c}6.81 \pm 1.26 \\
(5.84,6.89,7.87)\end{array}$ & $\begin{array}{c}7.19 \pm 1.50 \\
(6.43,6.76,7.91)\end{array}$ \\
\hline$\Delta \mathrm{E} \_8 \mathrm{~W}$ & $\begin{array}{c}12.18 \pm 2.34 \\
(10.54,12.29,13.05)\end{array}$ & $\begin{array}{c}5.35 \pm 1.79 \\
(3.37,5.97,6.34)\end{array}$ & $\begin{array}{c}10.21 \pm 1.02 \\
(9.75,9.85,10.34)\end{array}$ & $\begin{array}{c}18.36 \pm 2.28 \\
(17.18,18.43,20.32)\end{array}$ & $\begin{array}{c}13.07 \pm 1.08 \\
(12.21,13.08,13.78)\end{array}$ & $\begin{array}{c}22.22 \pm 4.45 \\
(18.63,19.99,27.75)\end{array}$ \\
\hline$\Delta \mathrm{E}_{-} 12 \mathrm{~W}$ & $\begin{array}{c}14.69 \pm 3.05 \\
(12.75,14.34,16.36)\end{array}$ & $\begin{array}{c}6.52 \pm 2.50 \\
(4.86,5.74,9.14)\end{array}$ & $\begin{array}{c}16.90 \pm 2.20 \\
(14.97,16.52,18.29)\end{array}$ & $\begin{array}{c}22.13 \pm 3.51 \\
(19.19,20.51,25.39)\end{array}$ & $\begin{array}{c}16.66 \pm 3.05 \\
(14.34,16.25,17.95)\end{array}$ & $\begin{array}{c}24.60 \pm 4.30 \\
(21.57,23.91,26.83)\end{array}$ \\
\hline
\end{tabular}

${ }^{*}$ The darker grey cell represent significantly greater color difference $(\Delta \mathrm{E})$ than that of light grey cell within each experimental group $(P<.05)$. It have shown the difference of $\Delta \mathrm{E}$ over time after staining with black tea and does not represent the difference among materials (Only longitudinally).

parameters of different objects. Although this method does not directly translate to clinical implications, previous studies used a similar protocol and considered it adequate. ${ }^{3-5,14-16}$

Eldiwany et al. ${ }^{17}$ reported that color difference $(\Delta \mathrm{E})$ could be visually distinguished when the value was 3.3 or more. Goldstein $e t a l^{18}$ reported that a $\Delta \mathrm{E}$ value of 3.7 or more exceeded the clinical tolerance limit. In this study, all results exceeded this value regardless of the experiment group and staining solution. This may indicate that all experimental provisional materials exceed clinical tolerance, and that color stability is inferior for long-term use. In addition, color differences of most materials increased with time and were more obvious in milled and 3D-printed materials.

In the guidelines for polymer-based dental restorative materials (ISO 4049), water absorption shall be less than 40 $\mu \mathrm{g} / \mathrm{mm}^{3}$ and solubility less than $7.5 \mu \mathrm{g} / \mathrm{mm}^{3}$. The overall results in this study met the requirements of the standard, which may indicate that these properties had little effect on color stability as a variable. However, the water storage period of the sorption test was one week, while the storage period of the staining solution was for 12 weeks. This issue may be clarified with further water sorption testing conducted with prolonged duration.

Different results among studies may be due to differences among products and concentration of solution used. In this study, the results for conventional materials varied depending on the staining solution. Alike was more stable in coffee, while the value changed significantly in tea during the 4th, 8th, and 12th weeks. On the other hand, Luxatemp was more stable in tea, while in coffee, the value significantly improved during the 8 th and 12 th weeks. Although there is no concrete explanation for such improvement, this phenomenon may be partially explained by the low water sorption rate. ${ }^{19}$ In this study, Luxatemp demonstrated the lowest water sorption result among groups. Elagra et al. ${ }^{8}$ have reported that CAD/CAM PMMA materials exert superior color stability; however, their study was conducted for only 7 days. In the present study, PMMA milling material exhibited similar results for 4 weeks, but the color difference increased sharply after 8 weeks and showed lower stability on long-term testing. The 3D printing materials used in this study (Veroglaze \& E-dent 100) showed high color difference between 1 and 12 weeks and showed lower stability from the early stage (1st week) than other materials. This result might be due to the remaining uncured layer even after post-curing due to the characteristics of 3D-printing fabrication. Few previous studies have reported on the color stability of 3D-printing materials, and further research is needed.

\section{CONCLUSION}

The degree of discoloration increased with time or has been associated with drinks that have pigments that can stain, and visually perceptible color difference value $(\Delta \mathrm{E})$ was demonstrated regardless of the materials and solutions. PMMA milling and 3D-printing materials showed more rapid change in discoloration after 8 weeks. Longer-duration observations may be necessary since the patterns of change with long-term observation varied.

\section{ORCID}

So-Yeon Song https://orcid.org/0000-0002-7738-5370

Yo-Han Shin bttps://orcid.org/0000-0003-0341-1078

Jeong-Yol Lee https://orcid.org/0000-0003-3079-0376

Sang-Wan Shin https://orcid.org/0000-0002-3100-2020

\section{REFERENCES}

1. Rosenstiel S, Fijimoto J, Land M. Contemporary fixed prosthodontics. 3rd ed. St. Louis: Elsevier, 2000. p. 381. 
2. Anusavice KJ, Philips R. Phillips' Science of Dental Materials. 11th ed. St. Louis: Elsevier, 2003. p. 145-6.

3. Sham AS, Chu FC, Chai J, Chow TW. Color stability of provisional prosthodontic materials. J Prosthet Dent 2004;91:44752.

4. Rutkunas V, Sabaliauskas V, Mizutani H. Effects of different food colorants and polishing techniques on color stability of provisional prosthetic materials. Dent Mater J 2010;29:16776.

5. Guler AU, Yilmaz F, Kulunk T, Guler E, Kurt S. Effects of different drinks on stainability of resin composite provisional restorative materials. J Prosthet Dent 2005;94:118-24.

6. Samra AP, Pereira SK, Delgado LC, Borges CP. Color stability evaluation of aesthetic restorative materials. Braz Oral Res 2008;22:205-10.

7. Rayyan MM, Aboushelib M, Sayed NM, Ibrahim A, Jimbo R. Comparison of interim restorations fabricated by CAD/ CAM with those fabricated manually. J Prosthet Dent 2015; 114:414-9.

8. Elagra MI, Rayyan MR, Alhomaidhi MM, Alanaziy AA, Alnefaie MO. Color stability and marginal integrity of interim crowns: An in vitro study. Eur J Dent 2017;11:330-4.

9. Dawood A, Marti Marti B, Sauret-Jackson V, Darwood A. 3D printing in dentistry. Br Dent J 2015;219:521-9.

10. Abduo J, Lyons K, Bennamoun M. Trends in computer-aided manufacturing in prosthodontics: a review of the available streams. Int J Dent 2014;2014:783948.

11. ISO 4049. Dentistry-Polymerbased restorative materials. International Standards Organization (ISO); Geneva; Switzerland, 2009.

12. Swaney AC, Paffenbarger GC, Caul HJ, Sweeney WT. American Dental Association specification No. 12 for denture base resin: second revision. J Am Dent Assoc 1953;46:54-66.

13. Carter EC, Ohno Y, Pointer MR, Robertson AR, Seve R, Schanda JD, Witt K. Commission Internationale de l'eclairage (CIE) 15:2004. Colorimetry, 3rd ed., CIE Central Bureau, Vienna, 2004.

14. Ergün G, Mutlu-Sagesen L, Ozkan Y, Demirel E. In vitro color stability of provisional crown and bridge restoration materials. Dent Mater J 2005;24:342-50.

15. Mickeviciute E, Ivanauskiene E1, Noreikiene V. In vitro color and roughness stability of different temporary restorative materials. Stomatologija 2016;18:66-72.

16. Haselton DR, Diaz-Arnold AM, Dawson DV. Color stability of provisional crown and fixed partial denture resins. J Prosthet Dent 2005;93:70-5.

17. Eldiwany M, Friedl KH, Powers JM. Color stability of lightcured and post-cured composites. Am J Dent 1995;8:179-81.

18. Goldstein GR, Schmitt GW. Repeatability of a specially designed intraoral colorimeter. J Prosthet Dent 1993;69:616-9.

19. Akashi A, Matsuya Y, Unemori M, Akamine A. The relationship between water absorption characteristics and the mechanical strength of resin-modified glass-ionomer cements in long-term water storage. Biomaterials 1999;20:1573-8. 